\title{
Business English Lingua Franca in intercultural (business) communication - By: ANNE
}

KANKAANRANTA

Posted by Michael Lambarena on February 272009 14:28:38

\section{Business English Lingua Franca in intercultural (business) communication}

Typically, the term intercultural is used as a synonym for international in the sense that it is used to refer to communication taking place between people with international backgrounds. Thus, a different cultural background equals to a different national background, which suggests that the communicators do not share the same mother tongue. In such situations the communicators basically have two options: first, one party can switch over to the other party's mother tongue; and second, both can use a common language which is neither party's native tongue. Both options call for intercultural communication.

Traditionally, speakers of smaller languages such as Finnish have had to resort to a number of foreign languages in order to do business with Spanish, French, German, and English speakers simply because in the international arena nobody speaks Finnish. Previously, in the corporate sector, only a few employees such as export or import managers had contacts across borders. A special group of foreign language experts, usually secretaries, dealt with business correspondence with international clients. Since language is closely intertwined with culture, this choice of the other party's native tongue meant that the non-native speakers had to adapt, for example, their discourse practices and non-verbal behavior to match those of the native speakers.

In today's business environment, the first option of switching over to the other party's native tongue in intercultural encounters is increasingly giving way to the second option: using a common language, a lingua franca. As we all know, the lingua franca of today's business world is English, which enables communication among business practitioners coming from a variety of cultural backgrounds. Recently, this phenomenon has also drawn attention in the popular press. For example, it was discussed at length in a Financial Times article of 11 Sept. 2007 called "Whose English?", which estimated that the number of native speakers of English is 
around 400 million, whereas one quarter of the world's population can communicate reasonably well in English. It has also been estimated that around $80 \%$ of all interactions in English take place between non-native speakers. In the business context, the reasons for this increasing usage of English lingua franca (ELF) are connected with the globalization of both business operations and communication technology. The recent wave of international mergers and acquisitions together with the emergence of new types of company networks and partnerships meant that a large proportion of members and employees of such entities had to be able to use ELF professionally, in other words, they needed to work in English. In multinational companies, English is typically the corporate language, which is used in such corporate functions as accounting, finance, management, and communications, whereas in the late 1980s 'Business English' was still mainly used with native English speakers in foreign trade transactions. ('Business English' can be defined as a subcategory of English, English for Specific Purposes or ESP, which was taught as the language used in business contexts.) Also, because of the huge advances in communication technology, it is easy to obtain personal contact across the globe via email, SMS messaging and the like in a matter of seconds. Thus, there is no need and no time for English language experts. All in all, we could argue that English plays the same role in multinational corporations as the mother tongue does in domestically operating companies or other monolingual work environments: it is used to get the job done.

To emphasize the increasing use of English in these intercultural business situations, we have called this language variety Business English Lingua Franca, BELF (see Louhiala-Salminen et al. 2005). BELF is used in the global business community to conduct business: it is a 'neutral' code used by business practitioners to do their work. Thus, it is not used at emulating native-speaker discourse but simply to get the job done. Indeed, it could be argued that BELF is a new professional language, which has emerged and occupied its niche in the past two decades. It is clearly different from 'Business English', which is a language to be studied and learned with the native-speaker model in mind. Although BELF communication can also be studied and learned to some degree outside its context of use (see Kankaanranta \& Louhiala-Salminen 2007), it is primarily a variety which is created in actual use because of its sensitivity to contextual constraints. The conception of BELF as a neutral professional language is not unproblematic, however (see e.g. Charles 2007). For example, some users will always be more proficient than others - not only because of their 'superior' English skills but also because of their highly effective business communication skills. Also, the relationship between culture and 
BELF is not a simple one. Meierkord (2002, p. 109) has presented two opposing views of the relationship between culture and the lingua franca. The first one argues that the 'neutrality' of the lingua franca code suggests that it is also 'culture-neutral' because its speakers do not share a particular cultural background. And the other one, which Meierkord agrees with, argues that it carries culture like any other language because every speaker using a lingua franca has a cultural background. Drawing on this, we could argue that BELF carries culture on two levels: BELF users share the international business culture but are separated by their personal, specific cultural background that is not typically identical to the cultural background of another BELF user.

In this article, I base my discussion on this latter view emphasizing BELF as a carrier of culture, which we have discussed thoroughly in the ESP journal article English as a lingua franca in Nordic corporate mergers: Two case companies (see Louhiala-Salminen et al. 2005). I thus argue that BELF communication is always intercultural: BELF speakers share the ' $\mathrm{B}$ ', i.e. the context and culture of business, the ' $E^{\prime}$, i.e. English and its discourse practices, but are separated by the culture connected with their various native tongues, their discourse practices, and particularly their hidden, implicit rules of communication.

The focus of this article is the use of BELF in intercultural business communication in the globalizing environment. I briefly present two major research projects housed at the Helsinki School of Economics (HSE), which focus on language and cultural issues in multinational corporations. Finally, I describe how we at HSE have been inspired by these projects to develop our courses in English and International Business Communication to meet the challenges of the globalizing business.

\section{Finnish, Swedish, or English? \\ In-house communication in recently merged Finnish-Swedish corporations}

The first research project carried out in 2000-2002 focused on company-internal communication and dealt with two corporate mergers over the Gulf of Bothnia. In both cases a Finnish company merged with a Swedish one in the late 1990s and two new corporations were formed (see Louhiala-Salminen et al. 2005). One of them is a globally operating paper manufacturer and the other a banking group whose markets used to be in Scandinavia but have since expanded to the Baltic countries. The paper company chose English as their corporate language and the bank initially opted for Swedish as the 'reporting language and the language for management'. At this point, it is essential to remember that 
Swedish is the second official language of Finland with some $6 \%$ of the population speaking it as their mother tongue.

The starting point for our research was to find out how the employees of the new entities coped with the new linguistic and cultural challenges of the cross-border mergers. We started with a communication survey and interviews in both companies to find out about their communication practices and, in particular, how the Finnish and Swedish employees perceived their each other's communication cultures. We then analyzed meetings and emails to see if, and how, the survey findings were reflected in authentic data. Here I primarily focus on some of the survey findings and on email messages written in English and exchanged between Finns and Swedes in the paper company.

The findings from the survey were based on around 400 responses from a randomly selected group of Finnish and Swedish employees in both companies (for the full report, see Louhiala-Salminen 2002). The respondents represented different organizational positions, units, and ages. The most interesting findings concerning intercultural issues are related to language choice on both the individual and corporate level and the perceptions about Finnish vs. Swedish communication.

On the individual level, language choice seemed to be a highly pragmatic one: English was used if the participants did not share a mother tongue. Around $20 \%$ of all internal communication took place in English and the rest in the respective mother tongue. Swedish was used to some extent in social settings.

On the corporate level, the bank's decision to use Swedish as the 'reporting language' was considered problematic, especially by the Finns. They pointed out how the Swedes gained the upper hand since they were able to use their mother tongue, whereas most Finns had to resort to a foreign language, which they felt they did not master so well. Finns applauded the change of the 'reporting' language to English a few years later when the bank expanded into Denmark.

The survey findings related to the Finnish and Swedish respondents' perceptions of each other's communication cultures seemed to support the anecdotal evidence of issue-oriented, direct Finns who are economical with words and people-oriented Swedes who enjoy talking. When Finns and Swedes described their own communication, they used positive language such as 'effective' vs. 'open discussion', whereas the characterizations of their partner's communication were more negative, such as 'too direct' vs. 'endless 
talk'. All in all, it was a question of how much talk was considered effective communication. Both Finns and Swedes considered their own communication effective and the other's less so. Although the respondents found it difficult to separate the impact of national, corporate, and organizational cultures, it was evident that BELF communication carried such characteristics that were explained by the cultural background of the user. Here it must be noted, however, that the survey questions might have guided the respondents to emphasize nationality as an explanatory factor.

\section{Email messages in BELF}

To find out how the perceptions about Finnish and Swedish communication were reflected in authentic data, 282 email messages written in BELF by the Finnish and Swedish employees of the paper company were investigated (for details, see Kankaanranta 2006). The analysis was based on the textualisations of 106 requests with a special focus on their directness to find out about the alleged 'directness' of the Finns and the nature of impositions to find out about the alleged 'discussion-orientation' of the Swedes.

In the data, every second request could be classified as direct, but the Finns were still somewhat more direct than the Swedes. Of all requests made by the Finns, 63\% were classified as direct using either imperatives (e.g. Please comment.) or questions (e.g. What do you think?), whereas the Swedes used more indirect forms such as modal initials (e.g. Could you please comment on this?). More interesting than the relative directness of the requests was the fact that both groups used expressions that the other one never used or at any rate used less frequently. One example of this difference is the use of kindly by the Finns to replace please; the Swedes never used it. Although the data was limited in size, it could be suggested that kindly is transference from the equivalent Finnish adverb ystävällisesti, which is an integral element in Finnish requests. For some Finnish speakers it may come more easily than please, which represents a functional equivalent for the adverb. What may confuse some Finnish speakers is the dictionary translation for please (olkaa hyvä), which is used when offering something, i.e. in the meaning of here you are. Another example of different usage is that the Swedes clearly used modal initials more than the Finns. To put it simply, when the Finns wrote Please comment on this, the Swedes preferred Could you please comment on this. More research is needed to further explore this difference.

The nature of impositions in the requests did not generate any clear differences between Finns and Swedes. Most of the impositions $(63 \%)$ called for communication-related activities: contacting 
people, informing them about something, and delivering something to them. Interestingly, one-fourth of all requests called for comments or opinions about other texts or business issues and was equally distributed among Finns and Swedes (see examples above). This result seems to suggest that discussion and dialogue were ongoing and extensive in the company and both Finns and Swedes could be described as discussion-oriented. When this characteristic is combined with the fact that first names were frequent in salutations and complimentary closes of the emails, we gain an image of a people-oriented, democratic corporate culture reflected in the actual use of BELF.

To sum up, the authentic email data supported the survey findings only to some degree and the same applies to the authentic meeting data (see Louhiala-Salminen et al. 2005).

\section{Does business know how? \\ The role of corporate communication in the operations of globalized companies}

The second major research project run by the International Business Communication unit at HSE started in 2006 and will continue until 2009. Its starting point is the idea of communication know-how as an integral component of business know-how in corporate activities. On a concrete level, we aim to characterize 'successful communication' in situations where BELF is used in multinational companies. One of the five subprojects (for more details, see http://www.hse.fi/EN/research/t/p 10/liike2/) comprises a questionnaire survey targeted at companies operating globally, and related interviews.

The ongoing project is a spin-off from the first one, since it inspired us to focus on BELF-related issues. Here I narrow my discussion to only three areas: the nature of English needed in international operations, the role of culture, and the persuasion strategies of BELF communication. At this point, I must emphasize the fact that we are still collecting data and our present data have not been systematically analyzed. So, the findings I will be briefly discussing next are preliminary and should be treated as such.

First, respondents with different cultural backgrounds working in internationally operating companies considered the English proficiency important and felt that BELF communication usually works well in situations where both parties are familiar with the topic. On the whole, communication with other non-native speakers was considered easier than that with native speakers. This finding is in line with the suggestion by Charles \& Marschan-Piekkari (2002), who argue that multinational corporations should invest in training 
their native English speaker employees to better understand and communicate with their non-native colleagues. Also, it could be argued that BELF speakers might well benefit from training in each other's specific discourse practices.

Second, it seems that in BELF communication culture plays an important role. However, although it is important to know both the organizational and national culture of the communicator, they are not considered as relevant as the knowledge of the other party's role in the organization. Comments supporting this finding were also obtained from email writers, who were not able to tell the nationality of some of their frequent communication partners (see Kankaanranta 2006). This finding is in agreement with Jameson's (2007) conception of individual cultural identity, in which nationality is but one component of many. Other such components are, for example, profession, education, religion, gender, and language.

Third, the respondents strongly agreed with the claim that such persuasion strategies as directness, explicitness, and politeness are important in BELF interactions; in particular, clarity was emphasized. They also stressed the importance of stepping into the other party's shoes and of making him/her feel good. Thus, successful BELF communication seems to remind us of Aristotle's rhetorical appeals and their importance in international business communication as discussed by Campbell (1998). In particular, logos appeals are considered crucial: facts must be presented clearly, explicitly, and directly. Pathos appeals, i.e. appealing to the emotions of the audience, on the other hand, can be exploited to ease the possible cultural hiccups, since the attempt to be polite and to make the other party feel good are bound to pave the way for successful communication. And as mentioned earlier, the fact that knowing the role of the communicator was regarded as essential can be interpreted as emphasizing the ethos appeal.

To sum up, these and other emerging findings will be subject to further analyses and will be complemented with interview data. Finally, we aim at characterizing the prerequisites of successful international communication.

\section{The future of intercultural business communication}

Practitioners and trainers alike should approach intercultural business communication from a new perspective, the BELF one, which would make the specific aspects related to the use of English in intercultural business encounters explicit.

First, the BELF perspective would emphasize the fact that BELF is used for doing business among people who are members of the 
global business community. In other words, all BELF users share the ' $\mathrm{B}$ ', i.e. the context and culture of business. Because business is a highly goal-oriented activity, communication skills become crucial in order to achieve the goal. Second, it would emphasize the fact that BELF is nobody's mother tongue. This feature will naturally emphasize not only the need for appreciating different types of English, accents and pronunciation in particular, but also the need for appreciating different discourse practices. Third, it would emphasize the need to learn and appreciate basic pragmatic phenomena, such as the use of politeness, and rhetorical appeals. In particular, emotional appeals (pathos) and attempts to make the other party feel good can effectively bridge the gap between speakers coming from different cultural backgrounds. Plus, closely related to the previous point, the BELF perspective would also emphasize the need for cultural sensitivity: understanding one's own cultural identity is a prerequisite for understanding that of others.

Inspired by the two research projects, we have modified our courses aimed at all B.Sc. (Econ.) students at the Helsinki School of Economics to meet the challenges of the globalizing business world more efficiently. Over the past ten years, we have changed our focus from 'Business English' to 'English business communication' with BELF as a natural starting point. In all our courses we aim to enhance our students' communication skills in an intercultural environment, which naturally calls for a strong emphasis on communication strategy including, in particular, the in-depth analysis of the audience (see Kankaanranta \& Louhiala-Salminen 2007).

In 2005, the European university degree reform resulting from the Bologna process gave us an exceptional opportunity to start a new Master's program in International Business Communication (see http://hse.fi/ibc/msc). The two-year Master's Program focuses on the strategic role of communication in the global operations of multinational corporations. Among other things, we aim to train communication professionals with an understanding of the role of BELF in corporate strategy implementation in intercultural environments.

As we all know, communication is challenging. It is challenging for people who have worked together for years and who share the same national, organizational and professional culture. It is bound to be even more so between people who, for example, become colleagues overnight because of a cross-border merger. Assuming the BELF perspective in such situations, and in other international encounters, it should pave the way for successful intercultural 
business communication.

\section{Author}

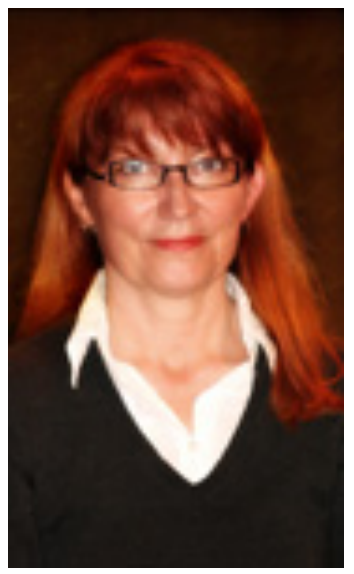

Anne Kankaanranta, Ph.D., MSc (Econ), is Senior Lecturer and Researcher of English Business Communication (undergraduate level) and International Business Communication (graduate level) at the Helsinki School of Economics. Her main research interests include the use of English as a business lingua franca and email genres in business communication. She serves on the Editorial Board of the Journal of Business Communication and has published in e.g., Business Communication Quarterly and English for Specific Purposes.

\section{References}

Campbell, C.P. 1998. Rhetorical ethos: A bridge between highcontext and low-context cultures? In S. Niemeier, C.P. Campbell \& R. Dirven (eds.), The Cultural Context in Business Communication, John Benjamins Publishing Company, 31-47.

Charles, M. (2007), Language Matters in Global Communication. The Journal of Business Communication, 44 (3), 260-282

Charles, M. \& R. Marschan-Piekkari (2002), Language Training for Enhanced

Horizontal Communication Training: A Challenge for MNCs, Business Communication Quarterly 65, 9-29.

Financial Times (2007), Whose English? Non-native speakers give a twist to the world's pre-eminent tongue, 11 Sept. 2007.

Jameson, D. A. (2007), Reconceptualizing cultural identity and its 
role in intercultural business communication. Journal of Business Communication, 44(3), 199-235.

Kankaanranta, A. (2006),"Hej Seppo, Could You Please Comment on This!" - Internal Email Communication in Lingua Franca English in a Multinational Company. Business Communication Quarterly, 69(2), 216-225. Full report available at http://ebooks.jyu.fi/solki/9513923207.pdf

Kankaanranta, A. \& Louhiala-Salminen, L. (2007).Business Communication in BELF. Business Communication Quarterly, 70 (1), 55-59.

Louhiala-Salminen, L. (2002), Communication and language use in merged

corporations: Cases Stora Enso and Nordea. Helsinki School of Economics Working Papers W-330. Helsinki: Helsinki School of Economics.

Louhiala-Salminen, L., M. Charles \& A. Kankaanranta (2005), English as

a lingua franca in Nordic corporate mergers: Two case companies, English for Specific Purposes. Special issue: English as a lingua franca international business contexts, C. Nickerson (ed.), 24/4, 401-421.

Meierkord, C. (2002), 'Language stripped bare' or 'linguistic masala'? Culture in

lingua franca conversation. In K. Knapp \& C. Meierkord (eds.), Lingua Franca Communication, Frankfurt am Main: Peter Lang, 109133.

This article was uploaded to http://www.languageatwork.eu in July of 2009 and published under a "Creative Commons license Attribution Non-commercial (by-nc)" for more information please go to: http://creativecommons.org/about/license/ 